\title{
Combating ovarian aging depends on the use of existing ovarian follicles, not on putative oogonial stem cells
}

\author{
Hua Zhang, Deepak Adhikari, Wenjing Zheng and Kui Liu \\ Department of Chemistry and Molecular Biology, University of Gothenburg, SE-405 30 Gothenburg, Sweden \\ Correspondence should be addressed to K Liu; Email: kui.liu@gu.se
}

\begin{abstract}
Ovarian aging is characterized by both a reduction in egg quality and a drastic reduction in the number of ovarian follicles. It has been generally accepted for 60 years that a fixed population of primordial follicles is established in the ovaries during early life, and in most mammalian species, oocytes cannot renew themselves in postnatal or adult life. This dogma, however, has been challenged over the past decade. In this review, we summarize the recent studies on primordial follicles and putative oogonial stem cells and discuss what resources in the ovary might be more reliable and promising source tools for combating ovarian aging.

Reproduction (2013) 146 R229-R233
\end{abstract}

\section{Introduction}

Ovarian aging is characterized by both a reduction in egg quality and a drastic reduction in the total number of ovarian follicles (Broekmans et al. 2007). In mammals, a fixed population of primordial follicles is established in the ovaries during early life and serves as the source of developing follicles and oocytes during the entire reproductive life of the organism (Zuckerman 1951). Regardless of whether new follicles are formed during adult life or not, it is firmly established that ovarian aging occurs inevitably over the lifespan of the organism. The reduction of oocyte quality with aging is believed to be mainly due to an increase in meiotic nondisjunction that leads to an increased rate of aneuploidy in the early embryos (Nagaoka et al. 2012). As a woman ages, her pool of primordial follicles also gradually but steadily shrinks and menopause occurs when the number of primordial follicles falls to below about 1000 (Faddy et al. 1992). Despite the gradual loss of primordial follicles over time, their relative abundance makes them an attractive source of material for fighting ovarian aging.

The issue of ovarian aging and its associated effects on fertility has received greater attention as an increasing number of women in modern society choose to postpone the age at which they bear children. In addition, cancerrelated mortality rates are decreasing due to advances in more effective treatments, but this has led to an increase in non-physiological ovarian aging because these treatments can adversely affect germ cell survival and cause premature ovarian failure (POF) and infertility (Jeruss \& Woodruff 2009).

\section{Primordial follicles: the natural source for fighting ovarian aging}

Despite the primary importance of primordial follicles in determining the reproductive lifespan and the rate of ovarian aging, very little is known about the molecular mechanisms regulating their development. Very recent studies using genetically modified mouse models, however, have made significant contributions to our understanding of how the development of primordial follicles is regulated. For example, studies from Dr Diego Castrillon's laboratory at the University of Texas Southwestern Medical Center and Dr Kui Liu's laboratory at the University of Gothenburg in Sweden have independently demonstrated that phosphatase and tensin homolog deleted on chromosome ten (Pten), a negative regulator of the phosphatidylinositol 3 kinase (PI3K) signaling pathway, serves as an essential inhibitory molecule that suppresses the activation of primordial follicles (John et al. 2008, Reddy et al. 2008). Deletion of the Pten gene that inactivates the protein leads to accelerated follicular activation and a rapid loss of the entire primordial follicle pool that renders the Pten mutant females infertile at young adulthood. Further studies by Kui Liu's group with genetically modified mouse models revealed a series of factors in the PI3K and mTOR signaling pathways (e.g., Pdk1, Tsc1, and Tsc2) that are actively involved in the regulation of primordial follicle activation and survival (for reviews, see Adhikari \& Liu (2009, 2010), Reddy et al. (2010) and Zheng et al. (2012)). These findings clearly show that the majority of primordial follicles must be kept in a quiescent state for 
later use in order to maintain the normal length of the female reproductive lifespan and to prevent accelerated ovarian aging. These results also suggest that the activation of primordial follicles might be enhanced if the inhibition of follicular activation can be effectively removed (Fig. 1A).

Ovarian tissue is rich in primordial follicles, which make up the majority of the total follicular population in the human ovary. Pioneering studies from Dr John Eppig's group in the Jackson Laboratory showed that live mice could be generated by in vitro culture of mouse neonatal ovaries that are rich in primordial follicles (Eppig \& O'Brien 1996, O'Brien et al. 2003). These experiments suggest the possibility of utilizing primordial follicles for fertility treatment.

In prepubescent girls who suffer from POF, ovarian tissue cryopreservation is the only fertility-preserving option because neither ovarian stimulation and collection of mature oocytes nor obtaining fertilized embryos is feasible (Hovatta 2004). With the aim of fighting ovarian aging and preserving fertility, there has been an increasing trend recently to cryopreserve ovarian tissues from young women (West et al. 2009). One technique that might have potential for fertility preservation, therefore, is to obtain mature eggs from the cryopreserved primordial follicles.

Based on the earlier findings that Pten plays a crucial role in primordial follicle growth (John et al. 2008, Reddy et al. 2008), two recent studies have independently reported the first attempts to activate primordial follicles in vitro with a synthetic small molecule that suppresses the activities of Pten (Li et al. 2010, Adhikari et al. 2012). These studies showed that primordial follicles from postnatal mouse ovaries can be successfully activated by administration of the Pten inhibitor and that these activated follicles can develop into mature and fertilizable oocytes when transplanted under the kidney capsules of recipient mice. These oocytes can give rise to healthy progeny mice, suggesting that it is safe to use the Pten inhibitor for the activation of primordial follicles (Li et al. 2010, Adhikari et al. 2012). In vitro culture of human cortical tissues in the presence of the Pten inhibitor also led to the activation of primordial follicles that yielded mature oocytes upon prolonged transplantation under the kidney capsule of recipient mice (Li et al. 2010). These experiments have significant clinical implications for dealing with ovarian aging using pre-existing primordial follicles as a source for obtaining fertilizable oocytes (Fig. 1A).

\section{'Oogonial stem cells' and postnatal folliculogenesis: more research is needed}

It has been generally accepted for more than 60 years that in most mammalian species oocytes cannot renew themselves in postnatal life and that the number of primordial follicles in the ovary is fixed at birth (Zuckerman 1951). This dogma, however, has been challenged over the past decade. Beginning in 2004, a series of studies from Dr Jonathan Tilly's laboratory at Harvard Medical School suggested that so-called 'oogonial stem cells (OSCs)' exist in postnatal ovaries.

In 2004, Tilly's group took their first shot against Zuckerman's dogma (Johnson et al. 2004). By counting
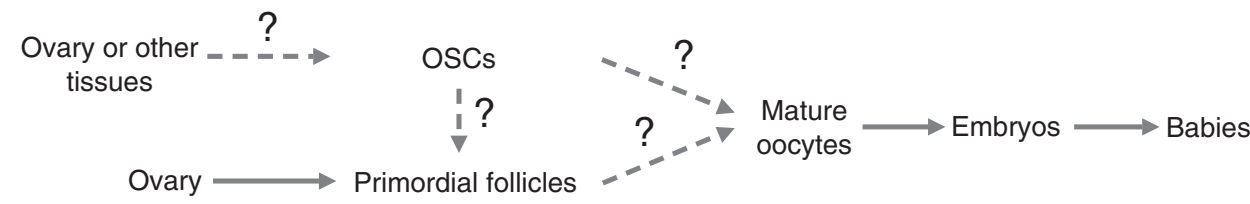

\begin{tabular}{|l|}
\hline A \\
Pros \\
1. The follicles are a well-characterized source. \\
2. The activation and development of primordial \\
follicles are better studied. \\
3. The follicles can be cryopreserved and transplanted \\
later to rescue fertility \\
4. Encouraging progress has been made toward \\
culturing primordial follicles in vitro. \\
Cons \\
1. The techniques for growing primordial follices to \\
mature follicles in vitro have not been well \\
developed, and this is a an uphill effort.
\end{tabular}

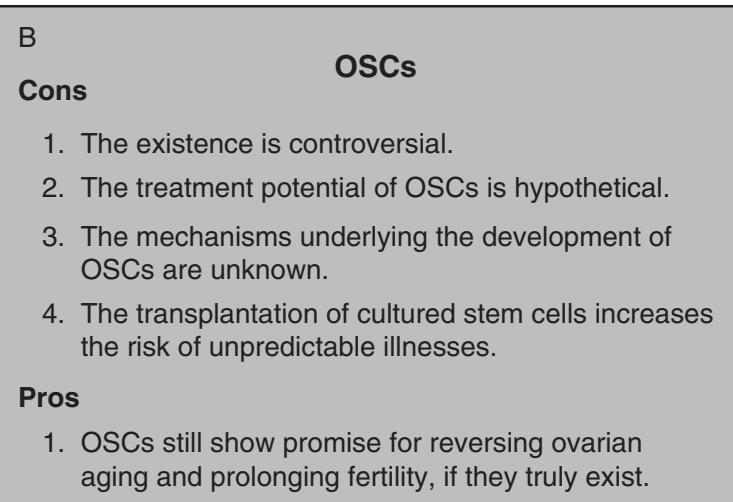

Figure 1 Comparison of the advantages and disadvantages of using primordial follicles or putative oogonial stem cells (OSCs) to preserve and rescue female fertility. Question marks indicate that these processes have not been well proven, and dashed arrows indicate that these steps have not been well developed. It is obvious that the primordial follicle is a more viable resource, and caution should be taken in suggesting putative OSCs for new infertility treatments before they have been fully investigated, if they exist at all. 
follicles, the authors proposed that primordial follicles in mice could be renewed at a rate of 77 follicles per day in each ovary. Moreover, they purported that a group of OSCs, which had originated from the epithelium of the ovarian surface, served as the source of the oocytes that fueled the follicular replenishment. Notably, these 'OSCs' were found to be mitotically active and were positive for the germline cell marker dead box polypeptide-4 (Ddx4). However, because many of the results in this study were confusing and could lead to divergent conclusions, critical comments were raised by other researchers immediately after the publication of this work (Albertini 2004, Gosden 2004, Telfer 2004). Several laboratories tried to repeat this work but they all failed to reproduce the same results (Bristol-Gould et al. 2006, Begum et al. 2008, Kerr et al. 2012).

One year later, in response to criticism from the field (Telfer et al. 2005), Tilly's group amended their previous report and claimed that the OSCs had actually originated from the bone marrow and peripheral blood (Johnson et al. 2005). In this study, Tilly's group reported that the cells from transplanted bone marrow or peripheral blood renewed the ovarian follicles and rescued the fertility of chemotherapy drug-sterilized female mice. Interestingly, the same germline cell marker, Ddx4, was employed in this work to identify the 'germline potent' bone marrow cells. Nevertheless, Johnson et al.'s postulation was soon refuted by another simple and straightforward study. Eggan et al. (2006) surgically joined the circulatory systems of a wild-type mouse and a mouse ubiquitously expressing green fluorescent protein (GFP) and found that no GFP-positive eggs were produced in the wildtype mouse (Eggan et al. 2006). Moreover, unpublished results from Kui Liu's laboratory using tracing technology after bone marrow transplantation from fluorescent reporter mice also showed that there was no oocyte renewal from the transplanted bone marrow, which confirmed Eggan et al.'s results (Eggan et al. 2006).

A major study was published in 2009 by Dr Ji Wu's laboratory at Shanghai Jiaotong University in China. Wu's group claimed that they had isolated a population of OSCs (referred to as female germline stem cells in their study) from postnatal mouse ovaries by magneticactivated cell sorting that was based on a polyclonal anti-human DDX4 antibody (Zou et al. 2009). These cells were $12-20 \mu \mathrm{m}$ in diameter and were round in shape. They were positive for several germline cell markers and could be stably passed more than 68 times when cultured in vitro, features that are found in spermatogonial stem cells. Notably, Wu's laboratory claimed that live mice were born from chemotherapy drug-sterilized female mice after these putative OSCs were transplanted into the ovaries of these mice (Zou et al. 2009).

No other groups were able to successfully reproduce Wu's results and obtain functional OSCs from postnatal mouse ovaries until 2012 when Dr Tilly's group published their isolation of mouse and human OSCs using the same DDX4 antibody-based cell-sorting system (White et al. 2012). Interestingly, the morphology of the OSCs obtained by Tilly seems to be distinct from the cells obtained by $\mathrm{Wu}$. The isolated OSCs from Dr Tilly's group were only 5-8 $\mu \mathrm{m}$ in diameter and were much smaller than embryonic primordial germ cells, male germline stem cells $(10-20 \mu \mathrm{m}$ in diameter) (Spiegelman \& Bennett 1973), and the cells obtained by Dr Wu's group (12-20 $\mu \mathrm{m}$ in diameter) (Zou et al. 2009).

Tilly's group also claimed that they had obtained human follicles by xeno-transplantation of human ovarian cortical tissues, which had been injected with human OSCs into immunodeficient female mice. They also claimed that mouse blastocysts had been obtained after transplantation of mouse OSCs into mouse ovaries. However, no functional human eggs or live mouse pups were generated in this work (White et al. 2012). Based on this finding, Dr Tilly claimed that 'cells with cell surface expression of DDX4 that are present in the ovaries of reproductive age women represent adult human OSCs' and that these 'might be useful for new fertility applications' (White et al. 2012).

This study soon attracted the attention of the mass media and patients, and it was believed that Tilly's study would open new doors for treating female infertility and postponing menopause. In contrast to this overoptimism, however, other researchers voiced their concerns (Oatley \& Hunt 2012) (http://www.bionews. org.uk/page_133180.asp). The major issue was the use of the human DDX4 antibody as the main tool to purify these purported OSCs. Ddx4/DDX4 is a cytoplasmic protein and is not known to be expressed on the cell surface (Tanaka et al. 2000). It is hard to understand, therefore, how the DDX4 antibody can bind to intracellular Ddx4/DDX4 protein and fish out the OSCs.

More recently, Dr Kui Liu's laboratory has traced the development of Ddx4-positive cells in mouse ovaries using Rainbow mice, a fluorescent reporter mouse model (Zhang et al. 2012). This tracing method is different from antibody-based cell sorting. It does not purify the cells but instead looks directly at the endogenous promoter activity of the $D d \times 4$ gene without any manipulation of the cells. Live-cell imaging showed that Ddx4-expressing cells in postnatal mouse ovaries did not proliferate when cultured in vitro, which was in direct contrast to the previously published studies (Zou et al. 2009, White et al. 2012). Recently, two new studies have confirmed the findings of Dr Liu. Using an inducible cell-lineage tracing method, Lei and Spradling from the Carnegie Institution for Science showed that no active 'OSCs' could be detected in adult mouse ovaries, and that the primordial follicle pool in a 4-week-old mouse ovary was sufficient to support fertility for the entire reproductive lifespan of the mouse (Lei \& Spradling 2013). In a non-human primate species, Yuan et al. from the Nankai University in China detected the mitotic and germline cell markers in monkey ovaries at different age by the 
Table 1 A list of studies reporting stem cells that can form oocyte-like cells.

\begin{tabular}{|c|c|c|c|c|c|c|}
\hline & \multirow[b]{2}{*}{ Origin of cells } & \multirow[b]{2}{*}{ Methods of isolation } & \multicolumn{3}{|c|}{ Germline developmental potential } & \multirow[b]{2}{*}{ References } \\
\hline & & & $\begin{array}{l}\text { Oocyte-like } \\
\text { cells }\end{array}$ & $\begin{array}{c}\text { Blastocyst-like } \\
\text { structure }\end{array}$ & $\begin{array}{c}\text { Live } \\
\text { offspring }\end{array}$ & \\
\hline \multirow[t]{4}{*}{$\begin{array}{l}\text { Putative oogonial } \\
\text { stem cells }\end{array}$} & Postnatal mouse ovaries & $\begin{array}{l}\text { Magnetic-activated cell sorting } \\
\text { with a DDX4 antibody }\end{array}$ & Yes & - & Yes & Zou et al. (2009) \\
\hline & $\begin{array}{l}\text { Postnatal mouse or } \\
\text { human ovaries }\end{array}$ & $\begin{array}{l}\text { Fluorescent-activated cell sorting } \\
\text { (FACS) with a DDX4 antibody }\end{array}$ & Yes & Yes & No & White et al. (2012) \\
\hline & Postnatal mouse ovaries & $\begin{array}{l}\text { FACS with a transgenic Oct4- } \\
\text { GFP-reporter mouse model }\end{array}$ & Yes & No & No & $\begin{array}{l}\text { Pacchiarotti et al. } \\
\text { (2010) }\end{array}$ \\
\hline & Postnatal mouse ovaries & $\begin{array}{l}\text { Whole ovarian cell culture } \\
\text { without any isolation }\end{array}$ & Yes & No & No & Hu et al. (2012) \\
\hline \multirow[t]{3}{*}{$\begin{array}{l}\text { Non-germline } \\
\text { stem cells }\end{array}$} & $\begin{array}{l}\text { Mouse embryonic stem } \\
\text { cells }\end{array}$ & - & Yes & Yes & No & Hubner et al. (2003) \\
\hline & $\begin{array}{l}\text { Mouse and porcine skin } \\
\text { stem cells }\end{array}$ & - & Yes & Yes & No & $\begin{array}{c}\text { Dyce et al. (2006) and } \\
\text { Linher et al. (2009) }\end{array}$ \\
\hline & $\begin{array}{l}\text { Pancreatic stem cell line } \\
\text { from male rats }\end{array}$ & - & Yes & No & No & Danner et al. (2007) \\
\hline
\end{tabular}

immunostaining method, and found no proliferated germline stem cells in postnatal ovaries of rhesus monkeys (Yuan et al. 2013). These lines of evidence further support the notion that no OSCs exist in postnatal mammalian ovaries (Fig. 1B).

Two other studies have also reported the isolation of OSCs from postnatal mouse ovaries (Pacchiarotti et al. 2010, Hu et al. 2012). However, these putative OSCs could only form morphologically oocyte-like cells in vitro and no meiotically competent functional oocytes could be generated. Nevertheless, the capability to form such oocyte-like cells is not unique to the putative OSCs. Embryonic stem cells (Hubner et al. 2003) and somatic stem cells from other organs (Dyce et al. 2006, Danner et al. 2007, Linher et al. 2009) have also been reported to form non-functional oocyte-like cells or blastocyst-like structures during in vitro culture (Table 1). The nature of these purported OSCs, therefore, is highly questionable.

Based on the work to date, there is still a lack of comprehensive validation for the existence of OSCs in postnatal ovaries. Even if the OSCs do exist in postnatal mammalian ovaries, there is still a long way to go before female infertility could be treated by stem cell therapy. Thus, the resource we already have in the ovary - the existing follicles - is still the only hope that we can currently rely on for treating female infertility and fighting ovarian aging (Fig. 1).

\section{Perspectives}

The molecular mechanisms controlling the activation of primordial follicles have started to be revealed, mostly using genetically modified mouse models. However, very little is known about the developmental dynamics of primordial follicles under physiological conditions. Pregranulosa cells provide a unique environment in which the oocytes of primordial follicles can remain dormant for long periods of time in mammalian ovaries, but the molecular mechanisms regulating the differentiation of pregranulosa cells into granulosa cells are largely unknown. The role of pregranulosa cells in the activation of primordial follicles is also yet to be identified, and in-depth studies of these issues will be of great value to our understanding of the process of ovarian aging.

Despite the shortcomings with primordial follicles, even more is unknown about the putative OSCs and there is a lack of direct evidence regarding the nature of these cells. The location of OSCs in the adult mammalian ovary, the mechanisms regulating the proliferation and differentiation of the OSCs in vivo, and the physiological function of the OSCs in female reproduction are all mysteries (Fig. 1B). There is still a long way to go before the existence of OSCs can be fully accepted by researchers in the field and before such cells can be safely used in clinical practice.

\section{Declaration of interest}

The authors declare that there is no conflict of interest that could be perceived as prejudicing the impartiality of the review.

\section{Funding}

This research did not receive any specific grant from any funding agency in the public, commercial or not-for-profit sector.

\section{References}

Adhikari D \& Liu K 2009 Molecular mechanisms underlying the activation of mammalian primordial follicles. Endocrine Reviews 30 438-464. (doi:10.1210/er.2008-0048)

Adhikari D \& Liu K 2010 mTOR signaling in the control of activation of primordial follicles. Cell Cycle 9 1673-1674. (doi:10.4161/cc.9.9. 11626)

Adhikari D, Gorre N, Risal S, Zhao Z, Zhang H, Shen Y \& Liu K 2012 The safe use of a PTEN inhibitor for the activation of dormant mouse primordial follicles and generation of fertilizable eggs. PLOS ONE 7 e39034. (doi:10.1371/journal.pone.0039034) 
Albertini DF 2004 Micromanagement of the ovarian follicle reserve do stem cells play into the ledger? Reproduction 127 513-514. (doi:10.1530/rep.1.00247)

Begum S, Papaioannou VE \& Gosden RG 2008 The oocyte population is not renewed in transplanted or irradiated adult ovaries. Human Reproduction 23 2326-2330. (doi:10.1093/humrep/den249)

Bristol-Gould SK, Kreeger PK, Selkirk CG, Kilen SM, Mayo KE, Shea LD \& Woodruff TK 2006 Fate of the initial follicle pool: empirical and mathematical evidence supporting its sufficiency for adult fertility. Developmental Biology 298 149-154. (doi:10.1016/j.ydbio.2006. 06.023)

Broekmans FJ, Knauff EA, te Velde ER, Macklon NS \& Fauser BC 2007 Female reproductive ageing: current knowledge and future trends. Trends in Endocrinology and Metabolism 18 58-65. (doi:10.1016/j.tem.2007. 01.004)

Danner S, Kajahn J, Geismann C, Klink E \& Kruse C 2007 Derivation of oocyte-like cells from a clonal pancreatic stem cell line. Molecular Human Reproduction 13 11-20. (doi:10.1093/molehr/gal096)

Dyce PW, Wen L \& Li J 2006 In vitro germline potential of stem cells derived from fetal porcine skin. Nature Cell Biology 8 384-390. (doi:10.1038/ ncb1388)

Eggan K, Jurga S, Gosden R, Min IM \& Wagers AJ 2006 Ovulated oocytes in adult mice derive from non-circulating germ cells. Nature $\mathbf{4 4 1}$ 1109-1114. (doi:10.1038/nature04929)

Eppig JJ \& O'Brien MJ 1996 Development in vitro of mouse oocytes from primordial follicles. Biology of Reproduction 54 197-207. (doi:10.1095/ biolreprod54.1.197)

Faddy MJ, Gosden RG, Gougeon A, Richardson SJ \& Nelson JF 1992 Accelerated disappearance of ovarian follicles in mid-life: implications for forecasting menopause. Human Reproduction 7 1342-1346.

Gosden RG 2004 Germline stem cells in the postnatal ovary: is the ovary more like a testis? Human Reproduction Update 10 193-195. (doi:10.1093/humupd/dmh023)

Hovatta O 2004 Cryopreservation and culture of human ovarian cortical tissue containing early follicles. European Journal of Obstetrics, Gynecology, and Reproductive Biology 113 (Suppl 1) S50-S54. (doi:10.1016/j.ejogrb.2003.11.012)

Hu Y, Bai Y, Chu Z, Wang J, Wang L, Yu M, Lian Z \& Hua J 2012 GSK3 inhibitor-BIO regulates proliferation of female germline stem cells from the postnatal mouse ovary. Cell Proliferation 45 287-298. (doi:10.1111/ j.1365-2184.2012.00821.x)

Hubner K, Fuhrmann G, Christenson LK, Kehler J, Reinbold R, De La Fuente R, Wood J, Strauss JF III, Boiani M \& Scholer HR 2003 Derivation of oocytes from mouse embryonic stem cells. Science $\mathbf{3 0 0}$ 1251-1256. (doi:10.1126/science.1083452)

Jeruss JS \& Woodruff TK 2009 Preservation of fertility in patients with cancer. New England Journal of Medicine 360 902-911. (doi:10.1056/ NEJMra0801454)

John GB, Gallardo TD, Shirley LJ \& Castrillon DH 2008 Foxo3 is a PI3K-dependent molecular switch controlling the initiation of oocyte growth. Developmental Biology 321 197-204. (doi:10.1016/j.ydbio. 2008.06.017)

Johnson J, Canning J, Kaneko T, Pru JK \& Tilly JL 2004 Germline stem cells and follicular renewal in the postnatal mammalian ovary. Nature 428 145-150. (doi:10.1038/nature02316)

Johnson J, Bagley J, Skaznik-Wikiel M, Lee HJ, Adams GB, Niikura Y, Tschudy KS, Tilly JC, Cortes ML, Forkert R et al. 2005 Oocyte generation in adult mammalian ovaries by putative germ cells in bone marrow and peripheral blood. Cell 122 303-315. (doi:10.1016/j.cell.2005.06.031)

Kerr JB, Brogan L, Myers M, Hutt KJ, Mladenovska T, Ricardo S, Hamza K, Scott CL, Strasser A \& Findlay JK 2012 The primordial follicle reserve is not renewed after chemical or gamma-irradiation mediated depletion. Reproduction 143 469-476. (doi:10.1530/REP-11-0430)

Lei L \& Spradling AC 2013 Female mice lack adult germ-line stem cells but sustain oogenesis using stable primordial follicles. PNAS 110 8585-8590. (doi:10.1073/pnas.1306189110)

Li J, Kawamura K, Cheng Y, Liu S, Klein C, Duan EK \& Hsueh AJ 2010 Activation of dormant ovarian follicles to generate mature eggs. PNAS 107 10280-10284. (doi:10.1073/pnas.1001198107)
Linher K, Dyce P \& Li J 2009 Primordial germ cell-like cells differentiated in vitro from skin-derived stem cells. PLOS ONE 4 e8263. (doi:10.1371/ journal.pone.0008263)

Nagaoka SI, Hassold TJ \& Hunt PA 2012 Human aneuploidy: mechanisms and new insights into an age-old problem. Nature Reviews. Genetics 13 493-504. (doi:10.1038/nrg3245)

Oatley J \& Hunt PA 2012 Of mice and (wo)men: purified oogonial stem cells from mouse and human ovaries. Biology of Reproduction 86196. (doi:10.1095/biolreprod.112.100297)

O'Brien MJ, Pendola JK \& Eppig JJ 2003 A revised protocol for in vitro development of mouse oocytes from primordial follicles dramatically improves their developmental competence. Biology of Reproduction 68 1682-1686. (doi:10.1095/biolreprod.102.013029)

Pacchiarotti J, Maki C, Ramos T, Marh J, Howerton K, Wong J, Pham J, Anorve S, Chow YC \& Izadyar F 2010 Differentiation potential of germ line stem cells derived from the postnatal mouse ovary. Differentiation $\mathbf{7 9}$ 159-170. (doi:10.1016/j.diff.2010.01.001)

Reddy P, Liu L, Adhikari D, Jagarlamudi K, Rajareddy S, Shen Y, Du C, Tang W, Hamalainen T, Peng SL et al. 2008 Oocyte-specific deletion of Pten causes premature activation of the primordial follicle pool. Science 319 611-613. (doi:10.1126/science.1152257)

Reddy P, Zheng W \& Liu K 2010 Mechanisms maintaining the dormancy and survival of mammalian primordial follicles. Trends in Endocrinology and Metabolism 21 96-103. (doi:10.1016/j.tem.2009.10.001)

Spiegelman M \& Bennett D 1973 A light- and electron-microscopic study of primordial germ cells in the early mouse embryo. Journal of Embryology \& Experimental Morphology 30 97-118.

Tanaka SS, Toyooka Y, Akasu R, Katoh-Fukui Y, Nakahara Y, Suzuki R, Yokoyama M \& Noce T 2000 The mouse homolog of Drosophila Vasa is required for the development of male germ cells. Genes and Development 14 841-853.

Telfer EE 2004 Germline stem cells in the postnatal mammalian ovary: a phenomenon of prosimian primates and mice? Reproductive Biology and Endocrinology 2 24. (doi:10.1186/1477-7827-2-24)

Telfer EE, Gosden RG, Byskov AG, Spears N, Albertini D, Andersen CY, Anderson R, Braw-Tal R, Clarke H, Gougeon A et al. 2005 On regenerating the ovary and generating controversy. Cell 122 821-822. (doi:10.1016/j.cell.2005.09.004)

West ER, Zelinski MB, Kondapalli LA, Gracia C, Chang J, Coutifaris C, Critser J, Stouffer RL, Shea LD \& Woodruff TK 2009 Preserving female fertility following cancer treatment: current options and future possibilities. Pediatric Blood \& Cancer 53 289-295. (doi:10.1002/pbc. 21999)

White YA, Woods DC, Takai Y, Ishihara O, Seki H \& Tilly JL 2012 Oocyte formation by mitotically active germ cells purified from ovaries of reproductive-age women. Nature Medicine 18 413-421. (doi:10.1038/ $\mathrm{nm} .2669)$

Zhang H, Zheng W, Shen Y, Adhikari D, Ueno H \& Liu K 2012 Experimental evidence showing that no mitotically active female germline progenitors exist in postnatal mouse ovaries. PNAS 109 12580-12585. (doi:10.1073/ pnas.1206600109)

Zheng W, Nagaraju G, Liu Z \& Liu K 2012 Functional roles of the phosphatidylinositol 3-kinases (PI3Ks) signaling in the mammalian ovary. Molecular and Cellular Endocrinology 356 24-30. (doi:10.1016/j.mce. 2011.05.027)

Zou K, Yuan Z, Yang Z, Luo H, Sun K, Zhou L, Xiang J, Shi L, Yu Q, Zhang Y et al. 2009 Production of offspring from a germline stem cell line derived from neonatal ovaries. Nature Cell Biology 11 631-636. (doi:10.1038/ ncb1869)

Zuckerman S 1951 The number of oocytes in the mature ovary. Recent Progress in Hormone Research 6 63-109.

Received 11 May 2013

First decision 24 June 2013

Revised manuscript received 31 July 2013

Accepted 4 September 2013 